\title{
Training Global Managers to Prepare and Train Expatriates for More Efficiency and Effectiveness
}

\author{
Bob G. Barrett, Member, IEDRC
}

\begin{abstract}
While many employees have become expatriates and traveled thousands of miles to represent their companies and organizations in overseas ventures and start-up new locations, a common problem experienced by many is the lack of proper training and preparation. The cause for this ill-preparation or training can be linked to many different causes, but the aim of this paper will be to focus on what can be done to break down the barriers of miscommunication or improper training (or lack of it) in order to help prepare and training global managers to better prepare their expatriate staff or better efficiency and effectiveness. The paper will examine the past and current ways expatriates have been recruited, selected, and trained for overseas placement. Then there will be a focus on what happens to the expatriate once he or she is overseas and the role and function of the global manager. Finally, the last segment of this paper will look at how expatriates deal with the process of repatriation and if it is effective or note. While some organizations have developed best practices in this area, not all organizations take the time to benchmark what other organizations have been doing to better prepare expatriates and global managers in these areas.
\end{abstract}

Index Terms-Expatriate, global management, online training, virtual management.

\section{INTRODUCTION}

What companies have learned over the years in many of their global ventures is that the "wheel does not need to be reinvented," but rather how it is used might be of more use to them in the future. In essence, they have learned from previous mistakes and those mistakes of others that it is important to capture their "learning" for later use and perhaps to save some time and money from more "roadblocks" and "slowdowns" in their business pursuits and expectations. Nonetheless, while many organizations are starting to wake up and realize the importance of having a learning organization that constantly monitors and tries to improve upon its current practices and strategies, as well as reflecting on lessons learned, they are starting to realize that there are some areas that need more improvement than others. For example, while many companies are seeing global ventures, they have learned from past experiences that there may be something missing in their approach and how they apply what they have learned from these errors. According to Senge (1990), "learning organizations [are] organizations where people continually expand their capacity to create the results they truly desire, where new and expansive patterns of thinking are nurtured, where collective aspiration is set free,

Manuscript received June 3, 2013; revised August 6, 2013.

Bob Barrett is with the School of Business at American Public University, Charles Town, WV 25414 USA (e-mail: docjob00@msn.com). and where people are continually learning to see the whole together." [1]

If companies and organizations tend to step back and realize that specific performance requirements are normally a set of requisites, conditions, and/or expectations that they have designed and developed from data collected and implemented by themselves, as well as learning form the best practices of others. The question that underlies all of this line of think is the level of personal development that their employees are permitted or even what they want to be permitted. On the other hand, how does this line of thinking in terms of designed conditions and expectations affect the value of their human capital and if their employees believe that they are valued. If employees are not considered in terms of their value and potential in the overall organization, then the organization may start to fail, or fall short, in their capacity as a learning organization. Thus, this leads into our examination and discussion of the importance of expatriates in today's organizations and the global marketplace. Also, do organizations and their expatriates see needs and wants that may or may not be accomplished during the periods of before, during and after their global assignments? Finally, can additional training and development contribute to successful expatriate assignments during these three distinct periods in expatriate's duration of his or her global assignment or not?

\section{EXPATRIATES AND NEED FOR ADDITIONAL TRAINING}

While many expatriates may feel distanced from their main organization and lacking in proper attention and/or training for their jobs in terms of skills and technology, there still appears a need for training and development at the onset, during, and after an overseas assignment. Consequently, many of these organizations are now expanding internationally, but yet building and maintaining a better working relationship with their company's expatriates.

As more companies start to realize a need to revisit how they train their expatriates in order to prepare them properly for the assigned overseas ventures, more and more academic institutions have started to re-examine their course offerings. This paper will highlight on how education institutions have started to redesign their business courses, especially in the fields of international human resource management and global management, to offer more real world applications and learning to help their adult learners gain and realize how training for international assignments need more attention, reflections, and updating.

This paper will overview how changes in one school's international human resource management course has made a difference in student's views on what is needed for today's 
expatriates, as well as alerting them to possible training needs of these employees before, during, and after their overseas assignment. This course has changed their final project from a research-based paper to an applications-based activity where the learner develops more ownership and value with this learning endeavor. In this approach, the learner is given an overview of the international human resource management approach, then the student is required to participate in a project-based activity to create and design a two-part final project.

\section{INTERNATIONAL HUMAN RESOURCE MANAGEMENT (IHRM) PROJECT}

The project requires each student to create and design a potential intranet system with various forms, policies, and procedures to be used by both the expatriates working for the main headquarters in a particular country. The student proposes a country to focus on in order to gain research to help design an "appropriate" intranet design to address potential cultural, business, economic, and/or social perspectives, as well as addressing the needs of the HR, IT, and other departments of the main headquarters. The second part of the project requires the students to develop an electronic handbook (e-handbook) for use by the expatriate. The purpose of this e-handbook is for easy access of standardized HR policies, procedures, and contact information. While it may sound simplistic in design, it does require the students to select one specific country, design the two-part project, and then reflect on the overall process in a final weekly discussion forum.

Specifically, the student will have to examine how we can help workers to transit over to their new location as expatriates and find ways to ensure their success in an overseas location and new culture. It should be noted here that not all educational projects are as focused, this particular university has found that more adult learners tend to become more personally involve in the project, as they can see the project as a stepping stone to potential career success and development. Further, this project helps for students to see how current literature may not be as in depth in some areas of global expansion and expatriates as anticipated.

\section{SKILls NeEDED IN TODAY'S MARKETPLACE}

While many of us have seen technology evolving over the years in the workplace, the skills sets need for today's organizations and global marketplace has been changing. Harris (2000) stated that the "new workplace requires a new type of employee, one who is highly skilled, flexible, creative, and attuned to working as a member of a team" [2]. As more and more educational institutions have started to focus more on what the global business community needs, they have realized that there is a need for stronger skills sets in terms of global business and technology for both the students and instructors. This leads us to an important question for more academicians to consider. How can we better prepare our instructors and students to become better skilled and adaptable to today's ever-changing needs of the global workforce? Thus, this is the perspective of today's academic trainers and administrators as they brainstorm better ways to market and capture today's growing adult learning population. On the other hand, many instructors are starting to realize the need to modify their educational perspectives and reevaluate their teaching strategies and techniques for the changing needs of business, students, and academic standards.

While teaching in any environment may be a challenge for some instructors, it can be an equally challenge in both the face-to-face (F2F) and online learning environments. Thus, teaching in the virtual (online) learning environment does not have a clear-cut set of instructions. However, there is a stronger need for instructors to perform more functions, assume more roles, and be available more often than their counterparts teaching in brick-and-mortar classrooms. Even though many instructors are aware of the technological needs of their changing profession, they also have realized that there are other roles in which they need to perform and maintain in order to meet the various learning needs and objectives. Finally, they have realized that there are changes that are happening and need to be addressed. In 2000, the U. S. Department of Education noted that the following changes needed to be done. "Workplace education programs focus on the literacy and basic skills training workers need to gain new employment, retain present jobs, advance in their career, or increase productivity. Curricula are developed by educators, working with employers and employee groups, who assemble written materials used on the job and who analyze specific jobs to determine what reading, computation, speaking and reasoning skills are required to perform job tasks effectively. By their nature, successful efforts to institute workplace literacy programs require strong partnerships among educators, employers, and employees." [3] Consequently, many virtual (online) instructors are rethinking their approach to traditional homework and trying to "think outside of the box" as to what the student can carry with them. As noted earlier in this paper, we will look at how one university made changes to their international human resource management course to offer more "real world" application and help students to discover more with their own research efforts, as well as discuss how changes in this particular business field is constantly changing.

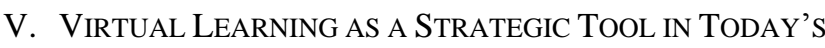 WORKPLACE}

While various economics have been changing, the global marketplace has seen many entities going global than ever before. As many of these organizations have rushed to open overseas locations, they are still faced with the realities of dealing with overseas locations in terms of different time zones, cultures, business practices, and customs, as well as dealing with socio-political factors. So, what does this mean to academia and business? While many businesses are relying more on virtual technology, and there appears to be a growing need for more training and education in the workplace, as well as for adult learners wishes to pursue further education for possible career change or upward mobility. Therefore, is there a need for virtual (online) 
learning in the workplace or not?

Many companies have been examining and trying out virtual learning to help bridge the gap between traditional training in order to meet different work hours, business commitments, as well as other external factors which may hinder the traditional approach to training. Historically, many companies have relied on the training component of their organization for training and transfer of learning for their expatriates before their departures to overseas locations. Thus, this leads us to the next questions as to what really is "distance education" and its potential application for today's business place? Neal and Miller (2006) defined distance education as "education that takes place independent of location, in contrast to education delivered solely in the classroom, and that may be independent of time as well (para. 4).[4] Further, the American Society of Training and Development (ASTD), an education/training \& development professional organization, noted that "distance education can be characterized as an educational situation in which the instructor and students are separated by time, location, or both. Education or training courses can be delivered to remote locations via synchronous or asynchronous means of instruction. [5] Consequently, many organizations have been using virtual learning and training for several years quite successfully. In fact, some of these companies have been creating virtual teams and virtual management to help accomplish their overall vision, mission, and ultimate organizational goals.

\section{ViRTUAL TRUST AND MANAGEMENT}

As noted earlier in this paper, there is a growing population of companies and organizations which have embraced the idea of online learning. On the other hand, there are those companies which are still a bit hesitant to make the transition over to this new area of learning offered via newer technological applications and equipment. The key reason for this hesitation has been in the areas of trust. We need to keep in mind that there are many HR professionals, especially HR managers, who may have varying levels of trust. They may not be as accepting of what is called "virtual trust." Thus, it is important to look at this topic and understand why trust, even in the virtual world, is equally as important as trust in the regular face-to-face (F2F) environment.

What is virtual trust and how does it differ in the virtual environment? Let us examine different types of trust. Uslaner (2001) noted that "Trust has a moral dimension—of ethically justifiable behavior as expectations. General trusters tend to have a higher ethical sensibility". [6] In addition, another type of trust is called swift trust. "Swift trust" tends to be unstable, fragile. This is when people (like adult learners) need to establish quick trust patterns with instructors, as in the online environment. In the virtual environment, virtual team members need to establish trust with their virtual manager, as well as their virtual group members. This type of trust may not be easily gained, and there could be a growing need for team building exercises, as well as interpersonal communications skills, if the group members are not able to establish a reasonable amount of virtual trust and communications flow at the onset and during their virtual projects. As a result, this paper will focus on the creation of potential learning applications to help assist the virtual manager and his or her virtual team.

Along this same line of thinking, the importance of management in the virtual environment is equally important. Therefore, what is virtual management and its impact in today's organizations? For the purposes of this paper, we will define virtual Management consists of the daily management of both the virtual team and workflow. It needs to be considered that as virtual teams are created, there is no real guarantee that all members will be productive, trustworthy, and/or technologically savvy. On the other hand, a good Human Resources Department should take the time to explore various learning approaches to help ensure proper virtual training to help new virtual team members to experience the virtual learning environment through the offer of online learning, as well as virtual exchanges.

Thus, many organizations have developed and designed online learning opportunities for their employees in order to show virtual team members how they can use technology to communicate, interact, and manage projects in a virtual environment with team members throughout the world. Therefore, this rest of this paper will focus on how Human Resource Managers can use online learning to help best prepare future expatriate employees to learn more about the culture, customs, business practices, and other pertinent information prior to their departure to their overseas work location.

\section{TRAINING FOR EXPATRIATES}

Not all training methods or approaches are effective in all organizations, and the use of best practices of others may not "fit" the particular learning needs of a company's employees. Thus, some companies and organizations are trying to "break these patterns" and instituting some changes in their recruitment and selection process of employees - especially those to work as potential expatriates. Barbara Smith (2000), chief learning officer for Burson-Marsteller stated that "If we don't have the best people creating the best product, we can't compete. What I'm after is creating the best people in the industry. E-Learning is an option that provides us with real competitive edge - it helps us maximize our intellectual capital." [7]. While technology may be breaking down current knowledge barriers and practices, it may be setting up others. One of the key barriers observed in some workplaces has been the lack of acknowledging the effect of errors and changes in an organization in terms of learning and creating more knowledge for the organization. Morgan (1986) addressed why it is important to accept errors and changes in order to learn from them. He stated that "Rather than create conditions which lead employees to hid or deny error and to avoid asking problematic questions, as often happens under bureaucratic systems of accountability, it is necessary to encourage them to understand and accept the problematic nature of the situation with which they are dealing. A philosophy that 'it is admissible to write off legitimate error against experience,' and that 'negative events and discoveries can serve as a source of knowledge and wisdom of great practice value,' is an example of the kind of stance required." 
[8]

As many companies have been reevaluating and looking at the value of their current workforce, especially in terms of potential expatriates, they have realized that business as usual cannot be the solution for their problems. Rather, they have to focus on what their employees can bring to the table, as well as what can they bring to the table to the employees? In essence, what can they do differently to retain their current employees, but yet attract even more qualified applications for their domestic and international hiring needs?

\section{QUID PRO QUO OR TIME FOR UPDATING}

Senge (1990) reinforced Argyris's line of thinking in terms of why corporate managers may find "collective inquiry inherently threatening." [9] Also, he stated that "School trains us never to admit that we do not know the answer, and most corporations reinforce that lesson by rewarding the people who excel in advocating their views, not inquiring into complex issues." [10] For the expatriate of former years, acceptance of orders and tasks was a mandate - not a choice. Employees did what they were "instruct" and never questioned issues or pursued the inquiry of questionable factors, issues, or decision - unless they were told to proceed in such a manner. Consequently, this has been changing over the past several decades in terms of employees starting to be given more empowerment and leverage to proceed with inquiry and perhaps profits from good findings in terms of merit bonuses and promotions. Clark and Mirabile (2004) summed; up a few of the realities that started to appear in the reshaping of key workplaces. They noted:

1) Work itself is being redefined. More emphasis is placed on lifelong learning, higher-order thinking, and an ever-increase demand for innovation.

2) The war for talent is an explicit condition of strategic business operations.

3) Companies specializing in some form of online training or knowledge management that did not exist five years ago have burst into the technology and service marketplace. [11]

As a result of this reevaluation and closer examination of the current environment and human capital, we have seen changes happening in the workplace as a result in changes in work processes and technology, we are also seeing changes in social capital. Daniel, Schwier and McCalla (2003) wrote that "Social capital is an imprecise social construct that has emerged from a rather murky swamp of terminology, but it is still useful for exploring culture, society and social networks. The notion of social capital originated from studies of conventional or temporal communities. Social capital highlights the central importance of networks of strong personal relationships that develop over a period of time." [12] As a result, while companies and organizations continue to grow and invest in technology, sometimes employees feel a disconnection between them and their own network of family, friends, and colleagues. Consequently, as they start to interface more with technology, they tend to question their worth and value in their respective places of employment. Therefore, it has become ever more important for more companies to focus more on retaining employees, especially focusing on potential expatriates (and retaining them during and after their overseas assignments). The key area that many companies focus on is preparing the expatriate for the upcoming overseas, which will be the main focus of the next section of the paper.

\section{A. Pre-Departure Period}

While many companies believe that they have learned from their mistakes, we have to wonder why they keep on repeating past mistakes. So, what makes a company a learning organization? According to Professor Mitleton-Kelly (2003) wrote "A learning organization is one that is able to change its behaviors and mind-sets as a result of experience. This may sound like an obvious statement, yet many organizations refuse to acknowledge certain truths or facts and repeat dysfunctional behaviors over and again".[13] Thus, how do organizations learn forom others and what should we be training our students to examine in this regard? Some organizations may just want to take the "quick fixe" approach, as noted by Senge (1995). While it should be noted that as some true learning organizations soon realize the benefits of trying "different approaches", others organizations may called themselves a learning organization without realizing that they are not "tapping into" their Intellectual Capital at its fullest potential.[14] Specifically, they may not realize the value and potential contributions of their human capital - and may not fully utilize all of their skills and abilities to the benefit of their organization and the employees overall. This is one of the reasons why some expatriates either want to quit for better jobs or return back to the main headquarters.

What are some approaches that organizations take to reexamine their approach to training and operation or just evaluate their strategies? Mitleton-Kelly (2003) noted that "Learning organizations encourage self-organization, so that groups can come together to explore new ideas without being directed to do so by a manager outside that group. This is the process that occurs naturally around the coffee machine or the water cooler, but learning organizations actively encourage self-organization and do not see it as a waste of time. This is an essential part of the innovative process which is also an integral part of creating an environment that facilitates co-evolutionary sustainability". [15]

In terms of preparing expatriates for upcoming overseas assignments, many companies are taking the time to reexamine the following factors that may affect current and future expatriates.

- Training programs

- Credentials

- Experience

- Competence

- Recruitment

- Mentoring

- Learning programs

- Individual potential

- Personality [16]

If we look at the university noted earlier in this paper and their final project approach, the main focus of the project is during the "before" stage for current and new expatriates. 
The adult learner has to design an Intranet system layout with forms, policies, and examples for use by the expatriate before and during their given global assignment. In addition, the students have to develop an electronic employee handbook ("e-handbook") for use by expatriates for the same time periods. The key focus of the course is to provide an overview of current best practices and strategies used by American companies, as well as international companies. Also, during this time, the students participate in weekly discussions, read various associated readings and websites, and conduct internet/library research on their select country and try to create a specialized project for academic credit, as well as a final project to share with potential employers. During this time, the instructor focuses the students from the phase of pre-expatriate preparation to the next phase of transitioning the expatriate to the assigned global location to be discussed in the next section.

\section{B. Expatriate and Departure}

As the expatriate relocates, along with or without their spouse and family, they may face a variety of issues, challenges, and topics not covered in the training. During this time, they be limited in their contact with others as a result of changes in time zones and limited in communication choices. However, due to the ever-changing technological offerings in today's global marketplace, the use of the Internet, Intranet, and electronic mail has helped to erase some of these barriers and limited opportunities. In the next section, we will examine this time period of work for the expatriate and the impact of additional training and use of a mentor to serve as a go-between the main headquarters and the overseas location.

\section{EXPATRIATES IN THE OVERSEAS ASSIGNMENT LOCATION}

Many companies have started to realize the importance of continued training for expatriates, as well as enlisting the use of a mentor for the expatriate during the crucial first few months of their assignment. In terms of training, as well as meeting the various challenges of time, distance, and availability, many companies are starting to lean towards and use various forms of online learning. At the end of 2006, 38 states in the United States have established state-led online learning programs, policies regulating online learning, or both. Also, 25 states have state-led online learning programs, and 18 states are home to a total of 147 virtual charter schools serving over 65,000 students. [17] (http://www.nacol.org). Further, we have seen that virtual (online) learning, or E-Learning, is not for all students, but it has afforded many companies a chance to creating learning opportunities for employees, both domestically and globally. Thus, the main thrust of this line of thinking is focused on what the company can do to help protect their investment in their expatriates, especially during this critical time, as well as demonstrate to their employees their value of their human capital? Consequently, one way that learning organizations can help show their interest with their global employees (expatriates) is offering additional training or mentoring to help keep them "connected" rather than "disconnected" from the organization. Thus, we need to examine more about mentoring in this context and how we can start to develop a mentoring process.

Like any type of training program, it should be done in phases. First, there needs to be a needs assessment. The organization, or training department, needs to find out if there is a need for mentoring program? If so, could there be a possible use for developing a virtual mentoring program to help not only virtual employees, but also fulfill the developmental needs of expatriates? Even though some companies may think that a mentoring program may be a solution, it may not be a need, but rather than a want. Nonetheless, if there is a need, then the next step is to design and develop the program.

It should be noted in this juncture of the paper that this is a good learning experience for adult learners taking an IHRM course, since many are perhaps been exposed to some form of mentoring in their current workplace and able to share with the class the pros and cons of various mentoring approaches. Also, instructors can use this particular topic as a key discussion forum question to help generate, or brainstorm, ideas about what makes a good or bad mentoring program.

\section{Developing a Mentoring Program for ExPatriates}

The creation of any training or mentoring program should be carefully planned and organized with not only the HR and training departments, but also with the members of management who might interact daily with the personnel in the overseas location. The key is to consider the learning objectives and limitations of the program in terms of technology, people, and training. Even though a mentoring program may be an idea solution in one sense, the mentors may need some training prior to the implementation of the program. For example, while a company may have many good employees to serve as mentors, they may not be using certain types of technology. Therefore, the company many need to create a training program for the mentors with no or limited technology knowledge. After the mentoring program has been created for implementation, these mentors should be at a given level to offer their mentoring skills and experience with virtual and expatriates. The key item that needs to be considered is that we are social creatures, and as such, distance and lack of one-on-one visual contact at times may affect one's performance levels.

According to the Expatcanada.org (2012), "Canadian Expats and former Canadian expats selected for this Program learn mentoring approaches and skills, and gain experience mentoring other Canadian expats, either those preparing to leave Canada, those recently relocated from Canada, or those preparing to return to Canada or who have recently returned. Mentors lend the benefit of their expat and repatriation experiences to their mentees and provide them with encouragement and social support. Those completing this Program will learn new listening techniques, and new motivation and persuasion practices. They will learn to adopt the best approach matched to the mentee's circumstances and personality and so more quickly build an effective relationship with the mentee".[18] Considering the Canadian approach here, they value the work experiences of their 
expatriates to help prepare and guide their current and future expatriates. In addition, rather than hiring external training resources or consultants, they realize the value of this segment of their human capital. Turtenwald (2012) further adds that mentoring for expatriates is not a one-time deal, but rather an ongoing event [19]. Rather, they may need on-going mentoring during their overseas assignment and before and after they return back to their home location.

While the next phase for an expatriate, the process of repatriation, is equally important, this has not been included as part of this paper. This is yet another area for future examination and research in the field of IHRM.

\section{Future ExPATRIATE TRAINING CONSIDERATIONS}

While economies, politics, and technology changes, so does the world of work and marketplace in general. What has worked in the business world during the past several decades may not work as well as today. Academics, especially virtual (online) instructors need to keep up to date with the many changes of technology, as well as facilitating learning according to the various types of learning styles with today's adult learners. The academic and business communities need to realize that the learning needs of today's learners have changed, as well as adult learners do have different learning styles. In addition, adult learners/employees need to see the utility and value in their learning, as well as a change in how learning is being offered and measured in today learning environment - whether it is in an academic or work setting. Furthermore, students want to have more ownership in their learning. As this paper has focused on how one university has changed their final learning project for their IHRM course, its main focus was on the training issues, challenges, and strategies for today's expatriate. Thus, this type of learning approach has added a more realistic and applicable type of learning approach to help students to become better prepared for the real world of work, as well as plan for their future.

\section{ACKNOWLEDGMENT}

I would like to acknowledge my mother, Margaret $\mathrm{M}$. Barrett Hendrickson, for all of her insights, experiences, and advice for this article in general, as well as for her guidance during my academic research pursuits. Sometimes we, as academics, tend to focus too much on one point, whereas, other points may lead us to yet further beginnings and areas of discovery.

\section{REFERENCES}

[1] P. Senge, The fifth discipline fieldbook: Strategies and tools for building a learning organization, pp. 3, 1994.

[2] H. Harris, "Defining the future or reliving the past? Unions, employers, and the challenge of workplace learning," Columbus, OH: ERIC Clearinghouse on Adult, Career, and Vocational Education, Information Series, no. 380, 2000.

[3] U.S. Department of Education, Fact Sheet 16, Washington, DC: Division of Adult Education and Literacy, Office of Vocational and Adult Education, USDE, March 2000.

[4] L. Neal and D. Miller. (2008). The basics of e-learning: An excerpt from Handbook of Human Factors in Web Design. In R.W. Proctor \& K.L. Vu (2004). Handbook of Human Factors in Web Design, Lawrence Erlbaum Associates. [Online]. Available: http://www.elearnmag.org/subpage.cfm?section=tutorials\&article=201.

[5] L. Neal and D. Miller. (2008). The basics of e-learning: An excerp from Handbook of Human Factors in Web Design. In R. W. Proctor \& K. L. Vu (2004). Handbook of Human Factors in Web Design. Lawrence Erlbaum Associates. [Online]. Available: http://www.elearnmag.org/subpage.cfm?section=tutorials\&article=201.

[6] E. M. Uslaner, "Volunteering and social capital: how trust and religion shape civic participation in the United States," in Social Capital and Participation in Everyday Life, edited by Eric M. Uslaner, pp. 104-117, London: Routledge, pp. 579, 2001.

[7] G. Koprowski. (July 10, 2012). Online Learning: The competitive edge. IW-Information Week. [Online]. Available: http://www.informationweek.com/801/prlearn.htm.

[8] G. Morgan, Images Organization, Sage: Newbury Park, pp. 91, 1986.

[9] P. Senge, The Fifth Discipline Fieldbook: Strategies and Tools for Building a Learning Organization, pp. 25, 1994.

[10] P. Senge, The Fifth Discipline Fieldbook: Strategies and Tools for Building a Learning Organization, pp. 25, 1994.

[11] S. Clark and R. Mirabile, "Knowledge mapping: An application mode for organizations," in M. Goldsmith, H. Morgan \& A. J. Ogg, Leading Organizational learning: Harnessing the Power of Knowledge, Jossey-Bass: San Francisco, pp. 113, 2004.

[12] B. Daniel, R. Schwier, and G. McCalla, "Social capital in virtual learning communities and distributed communities of practice," Canadian Journal of Learning and Technology, vol. 29, no. 3, pp. 113-139, 2003.

[13] E. M. Kelly. (October 3, 2011). What are the characteristics of a learning organization? [Online]. Available:
[ http://www.gemi.org/metricsnavigator/eag/What\%20are\%20the\%20 Characteristics\%20of\%20a\%20Learning\%20Organization.pdf.

[14] P. Senge, The Fifth Discipline Fieldbook: Strategies and Tools for Building a Learning Organization, 1994.

[15] E. M. Kelly. (October 3, 2011). What are the characteristics of a learning organization? [Online]. Available: http://www.gemi.org/metricsnavigator/eag/What $\% 20$ are $\% 20$ the\%20 Characteristics\%20of\%20a\%20Learning\%20Organization.pdf.

[16] Intellectual Capital: Tomorrow's Asset and Today's Challenge. (2009). As cited in T.A. Stewart, Intellectual Capital. New York: Doubleday Currency. [Online]. pp. 62-63. Available: http://www.cpavision.org/vision/wpaper05b.cfm.

[17] NACOL. (2009). [Online]. Available: http://www.nacol.org.

[18] Expatcanada.org. (November 1, 2012). http://www. expatcanada.org/index.php?option.com_content\&view=article\&id=48 \&lang=en.

[19] K. Turtenwald. Effective steps for mentoring expatriates. (Oct. 20, 2012). [Online]. Available: http://www.ehow.com/info_8040217_effective-steps-mentoring-expat riates.html

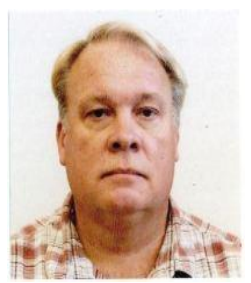

Bob Barrett was born in Hagerstown, Maryland, USA in 1962. He has an Ed.D in the field of Human Resource Development from The George Washington University in Washington, DC. He has done additional studies at Gallaudet University (for the Deaf and Hard of Hearing) in Washington, DC USA and University of Maryland - College Park. He has been teaching at American Public University for the past ten years, and he has been actively teaching online for the past twelve years. He is an adjunct instructor with other online programs, as well as a being a course developer and online teacher and trainer. His research interests include online learning, disability, teacher training, knowledge management, and intellectual capital. His specialization has been concentrated on human and intellectual capital, as well as knowledge management in the context of human resource management and human resource development. While he has been focused on the education of both military and civilian students, he particularly enjoys the teaching of organizational consulting, human resource management, human resource development, and strategic management. Dr. Barrett has worked in the both the private and public sectors, but he has been teaching online for the past twelve years. He has spoken extensively at various international conferences in Europe, South America, and Asia. Currently, he is working on chapters on lifelong learning, human capital, and disability for three different international books. 